\title{
CFD simulation of temperature and airflow inside a shipping container size plant factory for optimal lettuce production
}

\author{
${ }^{1 *}$ Mohd Noh, A., ${ }^{1}$ Mohamad Tahir, M.A., ${ }^{2}$ Mat, S. and ${ }^{1}$ Dzulkifli, M.H \\ ${ }^{1}$ Engineering Research Center, MARDI Head Quarters, 43400 Serdang, Selangor, Malaysia. \\ ${ }^{2}$ Solar Energy Research Institute, Universiti Kebangsaan Malaysia, 43600 Bangi, Selangor, Malaysia.
}

\author{
Article history: \\ Received: 27 April 2020 \\ Received in revised form: 19 \\ June 2020 \\ Accepted: 15 August 2020 \\ Available Online: 27 \\ December 2020
}

\section{Keywords:}

CFD simulation,

Plant factory,

Airflow distribution,

Temperature distribution

DOI:

https://doi.org/10.26656/fr.2017.4(S6).039

\begin{abstract}
Computational fluid dynamics (CFD) have been playing an increasingly important role in designing the agriculture control environment structure in the past few years. Plant factory is a fully enclose control environment agriculture structure developed to create optimum growing conditions for the crops. Previous studies have proven that the CFD technique was able to analyse and predict the internal climate of the plant factory in the designing stage before the actual plant was built. This study was conducted to analyse the changes in airflow characteristics and temperature distribution in a shipping container size plant factory with different inlet and outlet locations. Uniformity of airflow and temperature distribution was important in plant factories as it is responsible to create optimum and uniform growing conditions for crops. The CFD model was validated by comparing simulation and experimental data of existing plant factory inlet and outlet location. The validation result shows an acceptable percentage error between simulated and measured data. Two alternative design of the inlet and outlet location was simulated to improve the uniformity of airflow and temperature distribution. The validated CFD model was then used to simulate the alternative design. Finally, the location of the inlet and the outlet that produce the most uniform airflow and temperature distribution inside the plant factory was identified.
\end{abstract}

\section{Introduction}

Malaysia is a tropical country with a maximum daily temperatures hover between the $32.2^{\circ} \mathrm{C}$ and $35^{\circ} \mathrm{C}$ range most of the time. This condition is not suitable for lettuce growing. Plant factory was developed to enable planting of lettuce in Malaysia's low land area with higher temperature. Modifying the shipping container to become a plant factory is one of the option to build a plant factory with a minimal capital cost. The plant factory must be equipped with proper air conditioning and ventilation system to ensure it provides the required optimal environmental condition for lettuce to grow. Besides temperature, airflow is also one of the important factors in plant growth. A study by Kozai et al. (2015) proved that the air movement plays an important role in aerodynamics at leaf surfaces. It affects the gas, heat and water exchange of plants and thus affects plant transpiration and photosynthetic rates. The study found that increasing airflow speeds in both vertical and horizontal directions from 0.01 to $0.30 \mathrm{~ms}^{-1}$ around crops can significantly enhance the plant transpiration and photosynthetic rates. Horizontal airflow speeds above 1.0 $\mathrm{ms}^{-1}$ were suggested to achieve the maximal plant transpiration and photosynthetic rates of the crop canopy.

Understanding the internal airflow in a plant factory in detail is important to effectively deliver conditioned air to planting area to maintain climatic uniformity and promote adequate air movement around crops. In few cases, the uniformity of the temperature and airflow inside the plant factory can be lowered due to the increased number of layers of cultivation shelves, the increased resistance to airflow by plants and the excessive heat generated from the artificial lighting sources (Lim and Kim, 2014). Therefore, prior to designing the plant factory, the analysis of the airflow characteristics is a very important task to improve the uniformity of air temperature and humidity distribution.

Locations and sizes of the inlet and outlet and airflow speed from the inlet are very important factors for the environmental control of the closed plant production system. Particularly, the overall airflow characteristics can be greatly affected by the locations of the inlet and the outlet. Previous studies on the airflow 
pattern of closed space in the shape of a box, with different locations and sizes of the inlet and the outlet, have reported the obvious difference in airflow characteristics (Lim and Kim, 2014; Zhang et al., 2016; Niam et al., 2019). However, cost and time are required for attaining meaningful results that correspond to the optimal effect of the design parameters on the airflow and temperature pattern in greenhouses or plant factory, such as locations, sizes and airflow rate based on repeated experiments.

Physically measure the temperature and airflow using sensors at the different point around the crop is tedious and time-consuming. It also involves a high cost. Therefore, computer simulation is the solution. Computational fluid dynamics (CFD) are a computer simulation technique that has been shown to be an effective tool in simulating complex physical phenomena with reasonable accuracy. CFD has been widely used to study the ventilation and climate uniformity in greenhouses (Boulard and Wang, 2002; Bartzanas et al., 2004; Okayama, 2008; Lee et al., 2013; Tamimi et al., 2013). CFD studies to analysed ventilation and temperature in the indoor plant factory are increasing (Lim and Kim, 2014; Moon et al., 2014; Baek et al., 2016) but further studies for evaluating air-distribution system design alternatives in the indoor plant factory are required to improve climatic uniformity, especially for Malaysia's climate. Therefore, this study is focused on evaluating the cold air-distribution system design alternatives with particular focus on uniformity of climate inside the shipping container size plant factory with respect to air temperature and airflow according to local climate.

\section{Materials and methods}

\subsection{Experimental data collection}

Malaysia Agriculture Research Institute (MARDI) has successfully developed a shipping container size plant factory with a size of $2.6 \mathrm{~m}$ width $\mathrm{x} 4.6 \mathrm{~m}$ length $\mathrm{x}$ $2.5 \mathrm{~m}$ height. The container size plant factory was occupied with 2 units of 3 tier planting racks. The structure was enclosed. The climate inside the plant factory was controlled by an air-conditioner and outlet vent. The plant factory was equipped with two units of an air conditioner as the cold air inlet and one unit of exhaust fan as the outlet. Two units of air conditioner were required as the air need to be cooled 24 hours, therefore each unit will be switched on alternatively every 12 hours. Current location of the inlet and outlet is as shown in Figure 1. One of the air conditioners was located parallel to left rack and the other one is parallel to the right rack Temperature and airflow value at the inlet was measured to be the input value of the inlet properties in the CFD simulation. Temperature and airflow data from 12 locations in the plant factory was measured using Sper Direct mini-environment quality meter 850070 to validate the CFD simulation result. The locations are as shown in Figure 2. The point was located in the middle of both left and right rack with three different height which is low, middle and top. Validation was carried out by calculating the percentage error between the measured and simulated results. Percentage error was calculated by using the equation (1)

Percentage error $=\frac{\text { Simulated }- \text { Measured }}{\text { Measured }} \times 100$

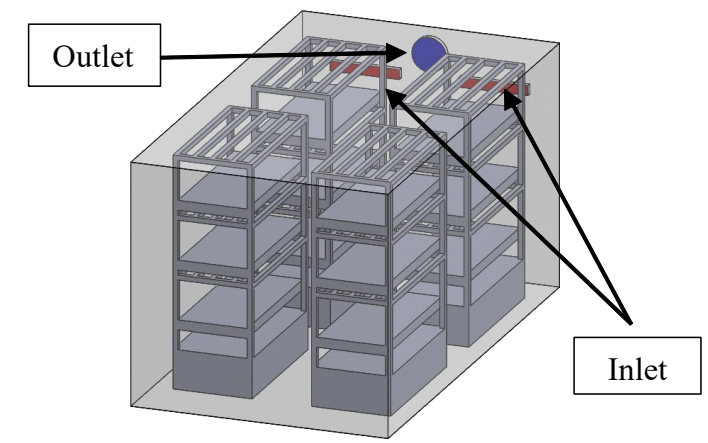

Figure 1. Shipping container size plant factory 3D drawing showing Inlet and outlet location

\subsection{CFD simulation}

In this study, the fluid flow in the plant factory was assumed to be a steady-state, incompressible and threedimensional turbulent flow. The numerical calculation of the temperature and airflow is generally based on the conservation equations of aerodynamics on (3) mass, (4) momentum and (5) energy. By enforcing these conservation laws over discrete spatial volumes in a fluid domain, it is possible to achieve a systematic account of the changes in mass, momentum and energy as the flow crosses the volume boundaries. In Ansys fluent the resulting equations can be written as below (ANSYS, Inc., 2011):

Continuity equation:

$\frac{\partial \rho}{\partial t}+\nabla \cdot(\rho \vec{v})=S_{M}$

Momentum equation:

$\frac{\partial}{\partial t}(\rho \vec{v})+\nabla \cdot(\rho \vec{v} \vec{v})=-\nabla p+\nabla \cdot(\overline{\bar{\tau}})+\rho \vec{g}+\vec{F}$

Energy equation:

$\frac{\partial}{\partial t}(\rho E)+\nabla \cdot(\vec{v}(\rho E+p))=\nabla_{\cdot}\left[k_{e f f} \nabla T-\sum_{j} h_{j} \vec{J}_{j}+\left(\overline{\bar{\tau}}_{e f f} \cdot \vec{v}\right)\right]+S_{h}$

The first three terms on the right-hand side of Equation (5) represent an energy transfer due to conduction, species diffusion and viscous dissipation, respectively.

The turbulent kinetic energy, $\mathrm{k}$ and its rate of dissipation, $\varepsilon$, are obtained from the following transport equations: 
$\frac{\partial}{\partial t}(\rho k)+\frac{\partial}{\partial x}\left(\rho k u_{i}\right)=\frac{\partial}{\partial x_{j}}\left[\left(\mu+\frac{\mu_{t}}{\sigma_{k}}\right) \frac{\partial k}{\partial x_{j}}\right] G_{k}+G_{b}-\rho \varepsilon-\gamma_{M}-S_{k}$

$\frac{\partial}{\partial t}(\rho \varepsilon)+\frac{\partial}{\partial x}\left(\rho \varepsilon u_{i}\right)=\frac{\partial}{\partial x_{j}}\left[\left(\mu+\frac{\mu_{t}}{\sigma_{\varepsilon}}\right) \frac{\partial \varepsilon}{\partial x_{j}}\right]+C_{1 \varepsilon} \frac{\varepsilon}{k}\left(G_{k}+C_{3 \varepsilon} G_{b}\right)-C_{2 \varepsilon} \rho \frac{\varepsilon^{2}}{k}+S_{\varepsilon}$

3-dimensional (3D) model of the plant factory was created using the solid works software. The 3D model was then imported to the ANSYS Fluent software for the simulation process of the airflow and temperature distribution. The configurations for CFD simulation is as shown in Table 1.

Table 1. CFD simulation configurations

\begin{tabular}{ll}
\hline Parameter & Setting \\
\hline Cell zone condition & \\
\hline Wall & Solid - polyurethane \\
Roof & Solid - polyurethane \\
Rack & Solid - steel \\
Internal domain & Fluid - incompressible air \\
Analysis type & Steady state \\
Gravity & $-9.81 \mathrm{~ms}^{-1}$ \\
Turbulence model & standard k- $\varepsilon$ \\
\hline Boundary condition & \\
\hline Air condioner inlet type & velocity-inlet \\
Air condioner velocity & 10.0 ms ${ }^{-1}$ \\
Air cond inlet temperature & 25 C \\
Floor & no slip wall, fix temperature \\
Wall & No slip wall, thermal-mix \\
& (convection and radiation) \\
Solution methods & SIMPLE (semi-implicit pressure \\
Momentum & 2nked equation) \\
\hline
\end{tabular}

\section{Results and discussion}

The simulation was carried out with only one air conditioner turn on which is parallel to the left rack because in the real situation at any time only one air conditioner was turned on to save the energy cost. The validation process was carried out by calculating the percentage error between the measured and simulated data at 12 locations as shown in Figure 2. The maximum percentage error between the measured and simulated data was $3.8 \%$. As the maximum percentage error was below $10 \%$, it can be concluded that the CFD simulation was able to represent the actual condition and can be used for further analysis.

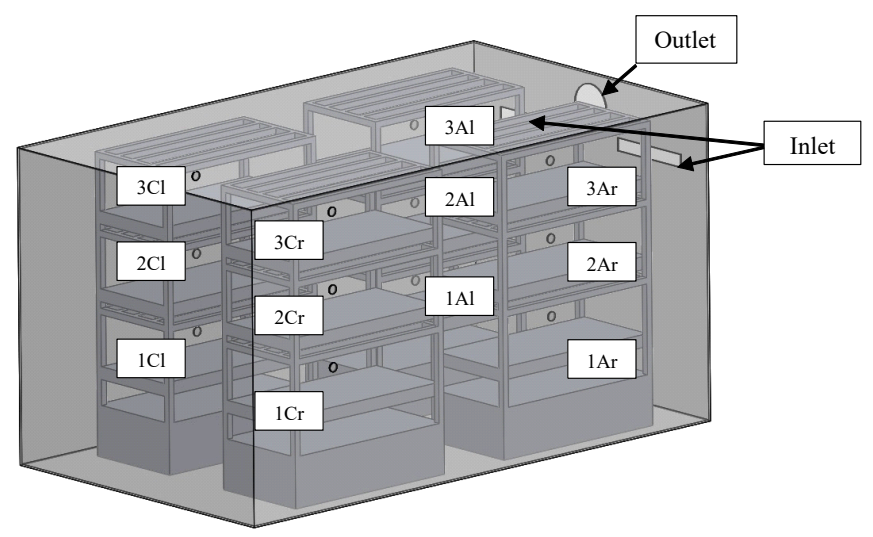

Figure 2. 12 data collection locations

In the current plant factory layout, the air conditioner was located parallel with the rack and this caused the cold air from the air conditioner flow directly in between the rack shelves. Figure 3 shows the CFD simulation results of temperature and airflow distribution of the current location of the inlet and the outlet. Figure 3 clearly shows an uneven distribution of temperature and airflow inside the plant factory. The airflow is high at the
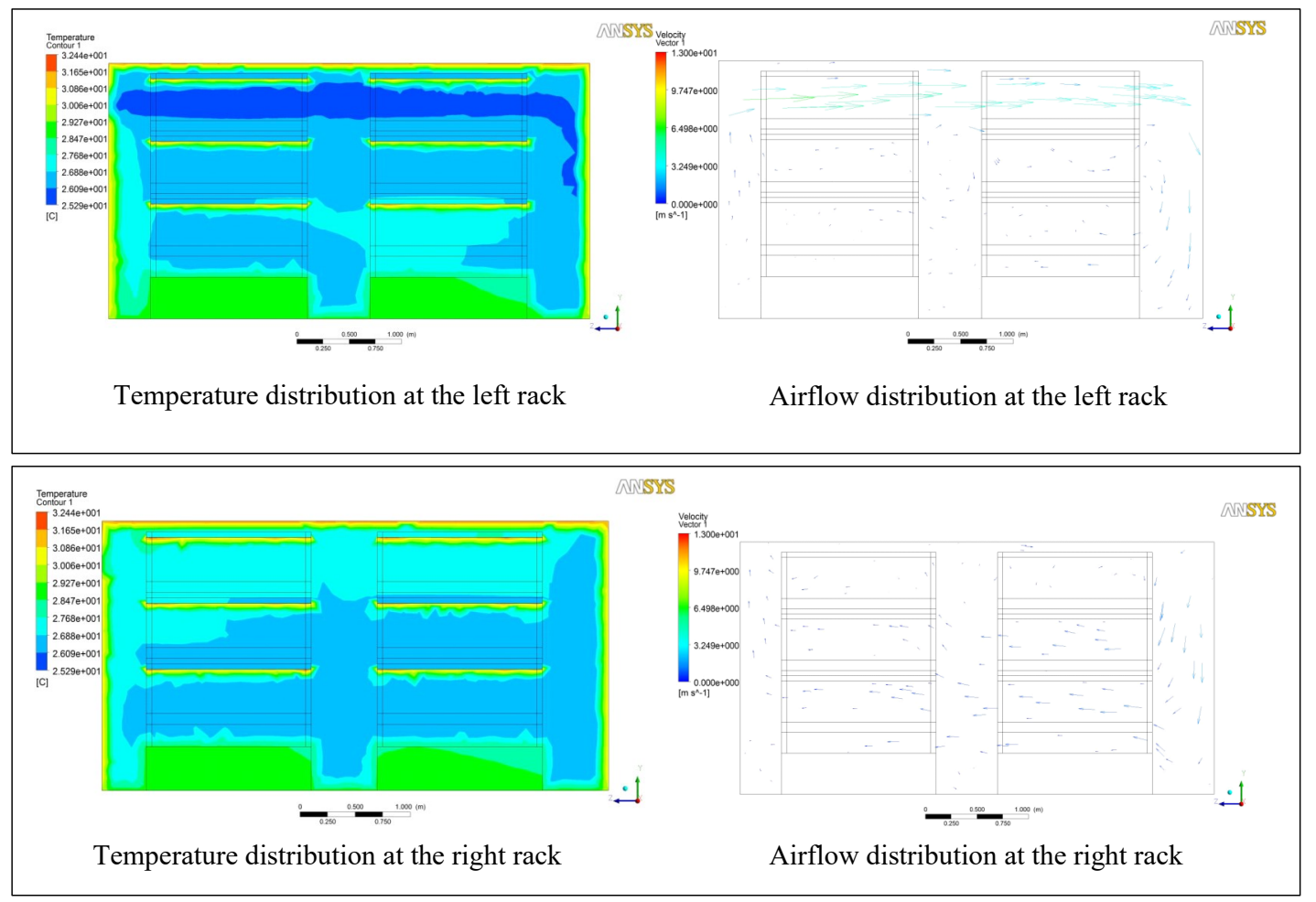

Figure 3. Temperature and airflow distribution contour for existing inlet and outlet location 

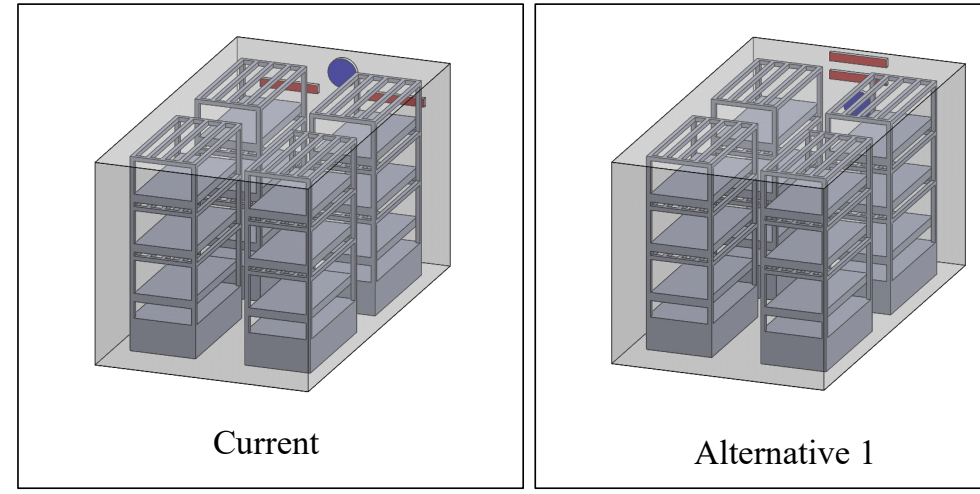

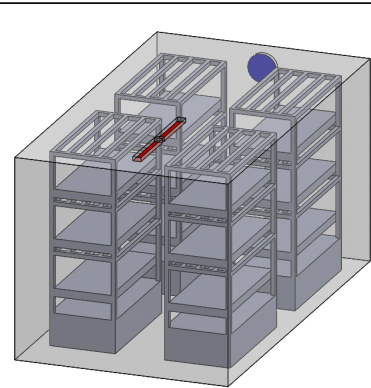

Alternative 2

Figure 4. Comparison between existing and alternative inlet and outlet layout of the plant factory

rack area parallel with the air conditioner inlet. While in another area, especially at the bottom shelves the airflow is low. This was directly related to the temperature distribution. The area where the airflow is high showing lower temperature while the area with low airflow is showing a higher temperature. This condition of uneven airflow and temperature distribution may cause uneven growth of the lettuce. Therefore, the 2 alternatives location of the cold air inlet and outlet was suggested as shown in Figure 4. For alternative 1 the cold air inlet was located in between the left and right rack and the outlet was located below the inlet. While for alternative 2 the cold air inlet was located on top of the container while the outlet location remains the same as the current location. Although Figure 4 shows 2 inlets, during the simulation only one inlet was turned on as in the actual situation at any time only one inlet was turned on the save electricity cost. CFD simulation was carried out to study the results of airflow and temperature distribution of both alternatives and the results are compared with the existing configuration.

Figure 5 shows the airflow distribution for the existing and alternatives inlet and outlet location. The Figure on the left side is the cross-section of the left rack while Figure at the right side is the cross-section of the right rack. The result shows that the airflow distributions for both alternative 1 and alternative 2 were more uniform compared to the current location. For both alternative 1 and 2, as the inlet was located in between the rack, the airflow was not being blocked by the rack, therefore the more uniform distribution of airflow was observed in between the shelves of the rack. To further compare the results between the existing and alternative inlet location, airflow data at 12 locations which are at the centre of every shelf for both right and left rack

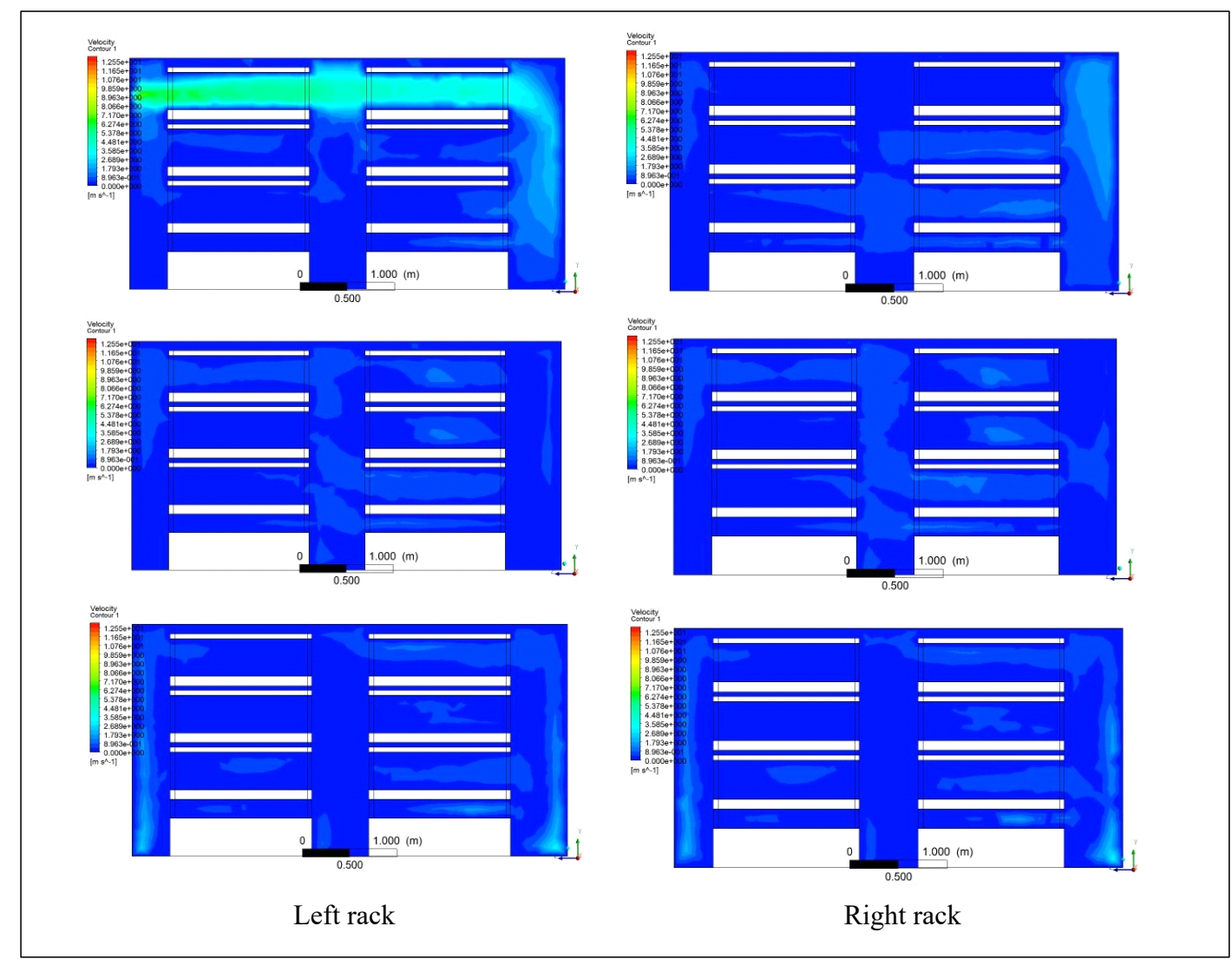

Figure 5. Comparison of airflow distribution in the plant factory between current (top), alternative 1 (middle) and alternative 2 (bottom) for the left and right rack. 
inside the plant factory was compared. Figure 6 shows the airflow data for these 12 locations. The data show that the maximum difference between the minimum and maximum airflow for the alternative location is lower compare to existing location, which is 5.5, 0.8 and 0.4 $\mathrm{ms}^{-1}$ for current location, alternative 1 and alternative 2 respectively. For current inlet location, the airflow value for $3 \mathrm{Al}$ and $3 \mathrm{Cl}$ was much higher because this two-point is directly parallel with the incoming airflow from the cold air inlet which is located parallel to the top area of the left rack.

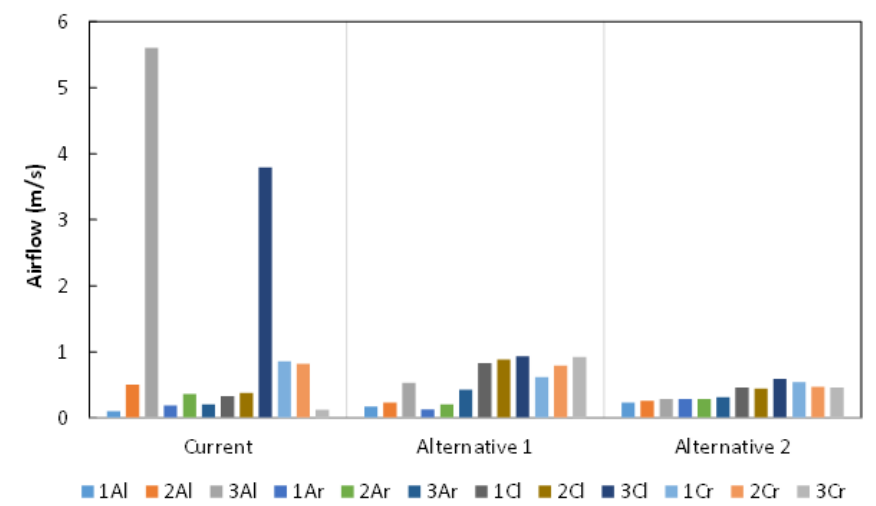

Figure 6. Comparison of airflow data for 12 points between all design options

The temperature distribution for the existing inlet location and alternative inlet location was shown in Figure 7. As the airflow pattern has directly affected the temperature distribution, Figure 7 clearly shows that alternative 1 and 2 produce more uniform temperature distribution compared to the current inlet and outlet location. This is because the uniform airflow distribution will enhance the cold air distribution inside the plant factory. Temperature data at 12 locations at the centre of every shelf for both right and left rack inside the plant factory was compared for all design. The temperature data for these 12 locations are as shown in Figure 8. The data show that the maximum difference between minimum and maximum temperature data for the alternative location is much lower compared to current location, which is $1.8,0.5$ and $0.5^{\circ} \mathrm{C}$ for current location, alternative 1 and alternative 2 respectively. However, for the average temperature, alternative 1 showing the lowest value which is $26.4^{\circ} \mathrm{C}$ while alternative 2 shows the highest value, which is $27.4^{\circ} \mathrm{C}$. Alternative 2 is producing higher average temperature because a large portion of the cold air from the inlet is flowing directly to the bottom of the container without circulating in between the shelves of both left and right rack as shown in Figure 9.

From the airflow and temperature distribution simulation results, inlet and outlet location for alternative 1 is the best configuration compared to other design. This is because it produces a more uniform distribution of airflow and temperature with lowest average temperature inside the container. Modification of the inlet and outlet location must be made following the alternative 1 layout to ensure uniform airflow and temperature that will produce more uniform growth of lettuce.

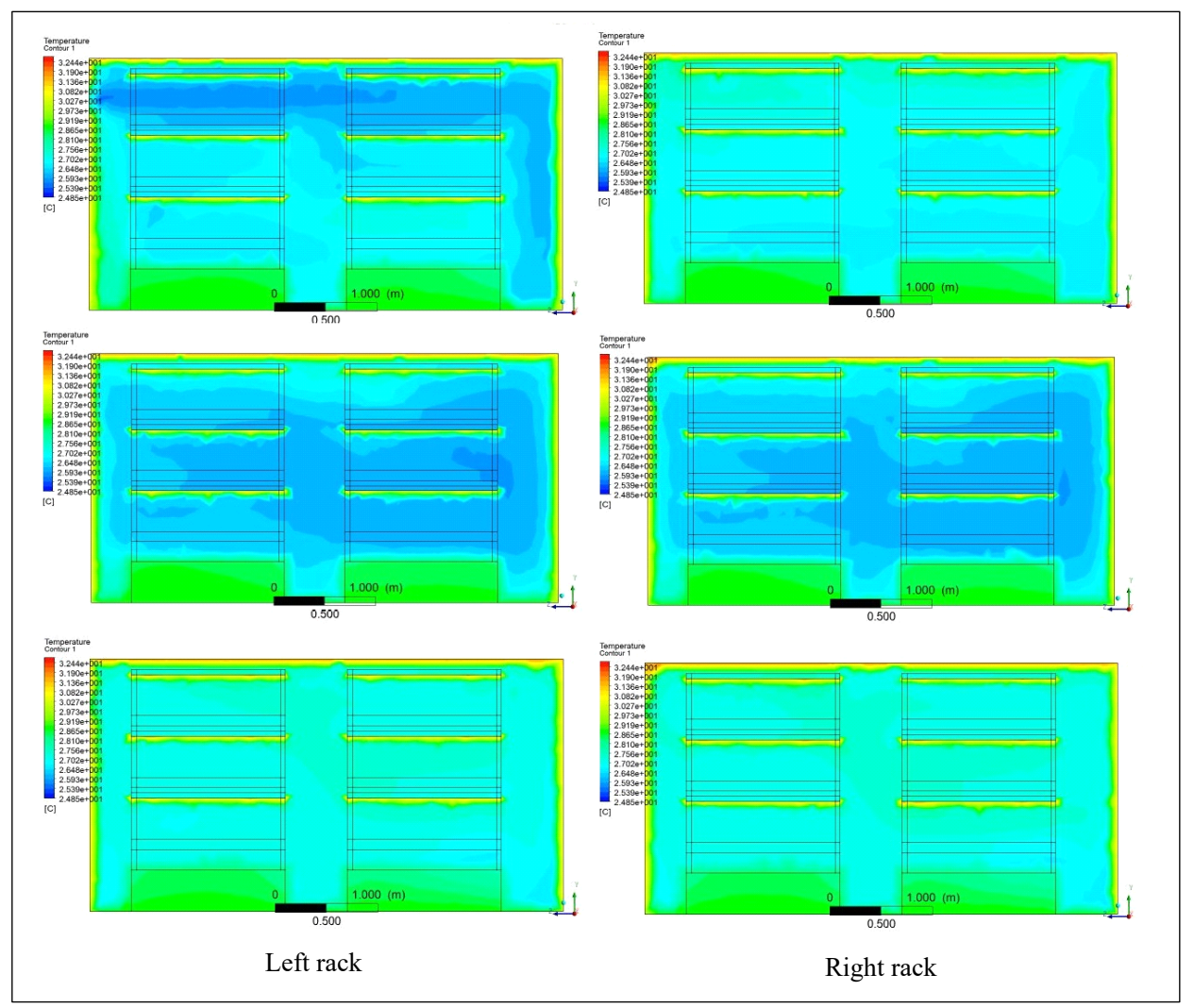

Figure 7. Comparison of temperature distribution in the plant factory between current (top), alternative 1 (middle) and alternative 2 (bottom) for the left and right rack 


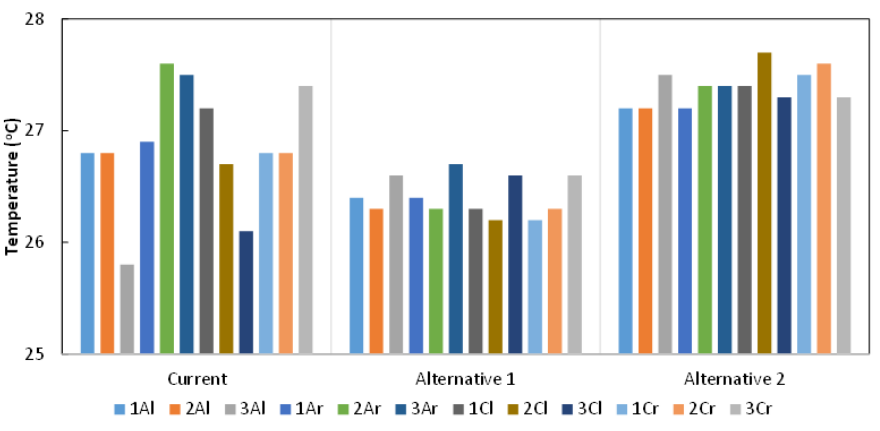

Figure 8. Comparison of temperature data for 12 points between all design options
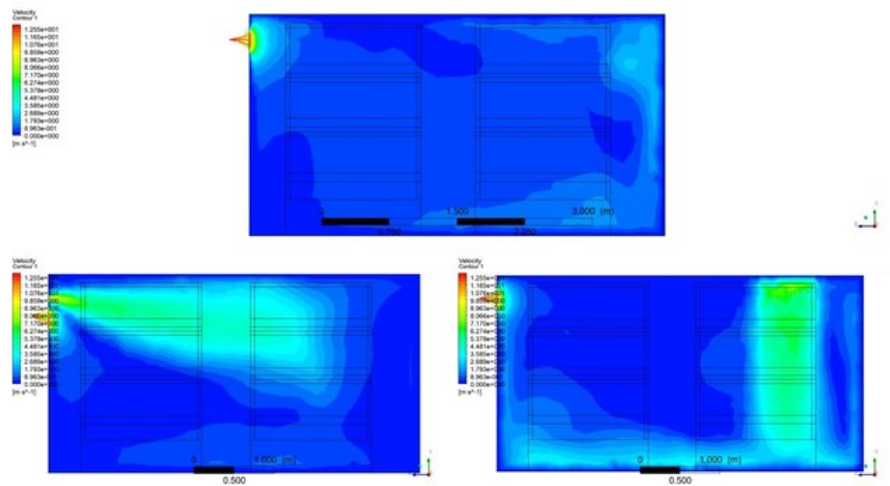

Figure 9. Comparison of airflow distribution in the plant factory between current (top), alternative 1 (bottom left) and alternative 2 (bottom right) at the center of the container

\section{Conclusion}

From the study it can be concluded that the CFD simulation able to represent actual conditions with acceptable accuracy. Therefore, the CFD also can be used to analyse the effect of different design, especially the effect of different cold air inlet and outlet location before the actual physical development. The study also concludes that changes in the inlet and outlet location affect the overall climate of the plant factory. The results from the study proved that the new location of inlet able to produce more uniform airflow and temperature inside the shipping container size plant factory with lower average temperature value.

\section{References}

ANSYS, Inc. (2011). ANSYS fluent theory guide, p. 724 -746. USA: ANSYS Inc.

Baek, M.S., Kwon, S.Y. and Lim, J.H. (2016). Improvement of the Crop Growth Rate in Plant Factory by Promoting Airflow inside the Cultivation. International Journal of Smart Home, 10(2), 63-74. https://doi.org/10.14257/ijsh.2016.10.2.07

Bartzanas, T., Boulard, T. and Kittas, C. (2004). Effect of vent arrangement on windward ventilation of a tunnel greenhouse. Biosystems Engineering, 88(4), 479-490.

https://doi.org/10.1016/ j.biosystemseng.2003.10.006

Boulard, T. and Wang, S. (2002). Experimental and numerical studies on the heterogeneity of crop transpiration in a plastic tunnel. Computers and Electronics in Agriculture, 34(1-3), 173-190. https:// doi.org/10.1016/S0168-1699(01)00186-7

Kozai, T., Niu, G. and Takagaki, M. (Eds.). (2015). Plant factory: an indoor vertical farming system for efficient quality food production. USA: Academic Press.

Lee, I.B., Bitog, J.P.P., Hong, S.W., Seo, I.H., Kwon, K.S., Bartzanas, T. and Kacira, M. (2013). The past, present and future of CFD for agro-environmental applications. Computers and Electronics in Agriculture, 93, 168-183. https://doi.org/10.1016/ j.compag.2012.09.006

Lim, T.G. and Kim, Y.H. (2014). Analysis of airflow pattern in plant factory with different inlet and outlet locations using computational fluid dynamics. Journal of Biosystems Engineering, 39(4), 310-317. https://doi.org/10.5307/JBE.2014.39.4.310

Moon, S.M., Kwon, S.Y. and Lim, J.H. (2014). Minimization of temperature ranges between the top and bottom of an airflow controlling device through hybrid control in a plant factory. The Scientific World Journal, 2014, 801590. https:// doi.org/10.1155/2014/801590

Niam, A.G., Muharam, T.R., Widodo, S., Solahudin, M. and Sucahyo, L. (2019, January). CFD simulation approach in determining air conditioners position in the mini plant factory for shallot seed production. In AIP Conference Proceedings, 2062(1), 020017. https://doi.org/10.1063/1.5086564

Okayama, T., Okamura, K., Park, J.E., Ushada, M. and Murase, H. (2008). A simulation for precision airflow control using multi-fan in a plant factory. Environmental Control in Biology, 46(3), 183-194. https://doi.org/10.2525/ecb.46.183

Tamimi, E., Choi, C.Y. and Ann, L. (2013). Analysis of microclimate uniformity in a naturally vented greenhouse with a high pressure fogging system. Transactions of the ASABE, 56(3), 1241-1254. https://doi.org/10.13031/trans.56.9985

Zhang, Y., Kacira, M. and An, L. (2016). A CFD study on improving airflow uniformity in indoor plant factory system. Biosystems Engineering, 147, 193205.

https://doi.org/10.1016/ 